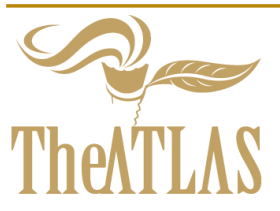

\title{
Being Transdisciplinary in Human Sciences: The usefulness of Integrative Medicine in contemporary society
}

Paulo Nuno Martins, Interuniversity Center for History of Science and Technology, New University of Lisbon, Campus of Caparica, Caparica, Portugal , Email:paulonunom@gmail.com

Received 15 June 2018; Accepted 26 July, 2018

Copyright (C)2018 Paulo Nuno Martins. This is an open access article distributed under the Creative Commons Attribution License (https://creativecommons.org/licenses/by/4.0/), which permits unrestricted use, distribution, and reproduction in any medium, provided the original work is properly cited.

Available online 30 July, 2018 at www.atlas-journal.org, doi: 10.22545/2018/00100

$n$ conventional medicine (Western medicine) the methods of healing are carried out externally through allopathic medicines (with several side effects), surgery and radiation (in the case of cancer) until the disease disappears - the biological dimension of the human being. However, Ayurveda (Eastern medicine) and mind-body medicine argues that the cause of some diseases, such as those in the psychiatric area (for example, a depression), is due to an imbalance between the mind (our thoughts, feelings) and the body, and so healing should also be done by the mind itself (through meditation, psychotherapy, etc.) in order to change the pattern of behavior that led to the disease (which is not relevant in Western and conventional medicine) - the psychological dimension of the human being

This "communication" is about the theme of conventional medicine (curative medicine) versus Ayurveda (preventive medicine) and mind-body medicine in order to describe the usefulness of integrative and transdisciplinary medicine - the bio-psycho-spiritual dimensions of the human beingthat might contribute to goal \#3 ("To ensure healthy lives and promoting well-being for all, at all ages") of the Sustainable Development Goals (SDG) of the United Nations 2030 Agenda.

Keywords: conventional medicine, Ayurveda (mind-body medicine), integrative medicine, goal \#3 of the Sustainable Development Goals (SDG) of the UN 2030 Agenda.

\section{Introduction}

One purpose of Integrative medicine [1] is to contribute to the connection of Eastern medicine (particularly Indian traditional medicine or Ayurveda) with Western medicine (conventional medicine) in order to develop a system of health care that might cure the entire person (bio-psycho-spiritual dimen- 
sions). Then, one application of Integrative medicine is to support goal \#3 ('To ensure healthy lives and promoting well-being for all, at all ages') of the Sustainable Development Goals (SDG) of the United Nations 2030 Agenda [2].

In this regard, I'm going to describe the historical roots of Eastern medicine and Ayurveda (preventive medicine) and the historical roots of Western and conventional medicine (curative medicine). There are three main historical roots for Ayurveda [3], namely, the History of Atharva-Veda, the Samkhya philosophy, the textbooks designated by Charaka Samhita and Sushruta Samhita. There are four main historical roots for conventional medicine [4], namely, the history of Hippocrates and Galen medicine, the contributions of Arabic medicine, the Cartesian dualism and mechanicism between mind and body, as well as some experiments performed in the brain area.

\section{The Historical Roots of Ayurveda: An Overview}

The Atharva-Veda is the last of the four Vedas (the Indian Holy Books) and is described over 20 books and some of them (called by "Samhitas") give a detailed description of the health sciences (human body anatomy, diseases, causes and the cure through medicinal plants) [5], [6]. The Ayurveda is a preventive medicine who cares for the patient as a whole and so, it states that health of a human being reflects the harmony of his/her lifestyle (the quality of sleep, food, thoughts and feelings) [7]. In this regard, the Samkhya philosophy (one of the six schools of Indian philosophy) applied to Ayurveda argues that is the "Ego/personality" that creates the unbalance/disharmony in the lifestyle of the human being [8]. Then, the analysis of mind-body relationship is made in Ayurveda through the "doshas" (vata, pitta, kapha) and "sub-doshas" [9]. The Ayurveda (from the Sanskrit,Ayur (means Life) and Veda (means Science)) which is described in the Hindu texts designated by Caraka Samhita (internal medicine treatise) and Sushruta Samhita (surgery treatise) [10], is a kind of mind-body medicine because the conscious mind plays a fundamental role in the process of self-healing (which is not relevant in conventional medicine) [11]. In Ayurveda, the process of healing is performed in different dimensions of the human nature as defended by the Panchakoshas theory [12].
There are some theories which support Ayurveda and the mind-body medicine, such as Holographic Mind theory (proposed by Karl Pribam and David Bohm) [13] and the Mind-Brain theory (proposed by Stuart Hameroff and Roger Penrose) [14]. The Holographic Mind theory claims that the mind (our thoughts, feelings) is a hologram, and the space-time reality is a "projection" made by the brain of this hologram (mental, emotional, vital patterns of behavior). In this regard, Amit Goswami [15] defends that the holographic mind might be described as "quantum waves of possibility".

The observation (or the choice) made by the subject (called by "wave function collapse") lead to the manifestation of holographic mind, namely, the disease or health. This means that disease and health are together inside us, that is, there is a unification of the subject (patient) and the object (disease or health) through the action of the Hidden Third (proposed by Basarab Nicolescu) [16]. The Mind-Brain theory also states that the "quantum component of the mind" (located in tubulins) is responsible for the change of the pattern of behavior that causes the disease, while the "classical component of the mind" (located in dendritic membranes) is responsible for the maintenance of health.

An example of the application of these theories which support Ayurveda might be seen in the different attitude of two people who need to deal with a problem (divorce, unemployment, death of a friend) [17]. One of them addresses this problem with positive thoughts and feelings (through meditation, psychotherapy) and so he/she might overcome the hard situation more strengthened by the experience. On the contrary, the other person has only negative thoughts, feelings and so he/she might have a depression. In summary, these two persons have different approaches to the same problem which leads to different health conditions for the two patients.

Ayurveda also defends that the process of healing is performed in the five dimensions of the human nature, as described by Panchakoshas theory. This description could be seen in Figure 1 [18]. These five plans of consciousness in human beings are: Annamaya Kosha (physical body), Pranamaya Kosha (vital or pranic body), Manamaya kosha (mind or thoughts/feelings), Vijnanamaya Kosha (intuitive knowledge), Anandamaya kosha (bliss or conscious linkage with the soul), Atman (soul). These several levels of consciousness might be related with the 


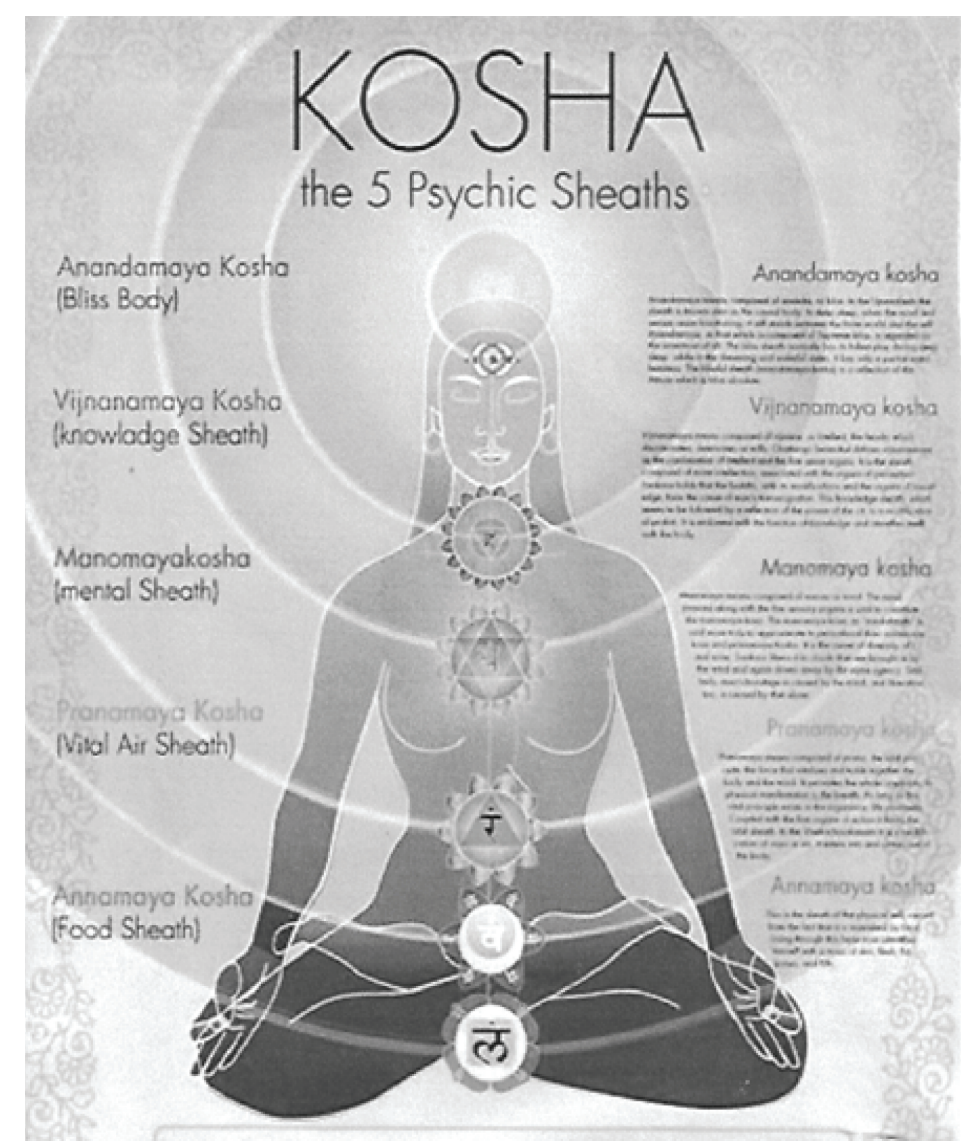

Figure 1: The plans of consciousness in the human being (Photo Source: Courtesy of Aaron Staengl).

"several levels of reality and complexity" proposed by Basarab Nicolescu [19]. Moreover, from the top to the bottom, we could see the seven main chakras (from the Sanskrit "wheel"), namely, Sahasrara (top of head), Ajna (inner vision), Vishuddha (throat), Anahata (heart) - the upper chakras- Manipura (solar plexus), Svadhistana (sexual), Muladhara (basic) - the lower chakras. The chakras operate according to the field of consciousness or perception of the observer/subject. If the field of consciousness is smaller, then the perception of reality is more limited and the subject has less possibilities of choice in his/her life. In this case, only the lower chakras are active. On the contrary, if the field of consciousness is greater, then the perception of reality is broaden and the subject has more possibilities of choice in his/her life. In this case, the upper chakras are also active [20]. We could make a comparison between the Figure 1, defended by Eastern thought, and the Figure 2 [21], defended by Western thought. In Figure 2, described by Roberto Assagioli as Egg's diagram [22], we could see the several areas of consciousness in the human mind. In psychology, consciousness with perception means self-awareness, while consciousness without perception means unconscious. In this regard, we could see the unconscious side of the human being (numbers 1,2,3 and 7), the field of consciousness (or the consciousness mind) of the human being (number 4) where appear the mental and emotional patterns of behavior (Jung called them Archetypes [23]), the "ego/personal I" (number 5) that might establish a conscious link with the soul (number 6).

\section{The Historical Roots of Conventional Medicine: An Overview}

Western and conventional medicine has its roots in Hippocratic medicine which sees the man as an organized unit constituted by four fluids, being the illness a reflection of an imbalance among these humors. Galen complemented these concepts through the use of medicinal herbs. Moreover, the Arabic medicine 


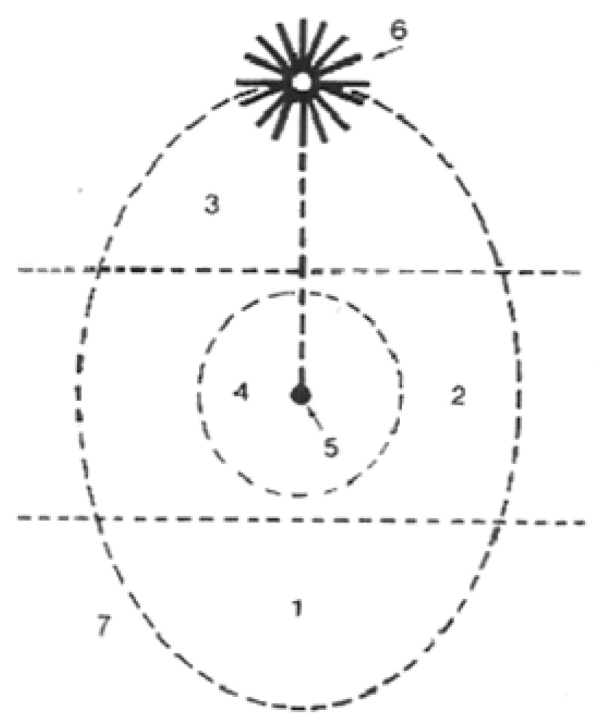

1. The Lower Unconscious

2. The Middle Unconscious

3. The Higher Unconscious, or Superconscious

4. The Field of Consciousness

5. The Conscious Self, or "i"

6. The Transpersonal Self

7. The Collective Unconscious

Figure 2: The areas of consciousness in the human mind (Photo Source: Courtesy of Kenneth Sörensen).

was responsible for the emergence of the concept of hospital, the compilation of various medicines and the development of surgical practices. Andreas Vesalius deepened the knowledge of the human body These ideas remained unchanged until the end of the $16^{\text {th }}$ century [24].

In the $17^{\text {th }}$ century, Descartes proposed the separation of mind ("res cogitans") and the body ("res extensa") - Dualism. The mind is the subject of activity of religion and philosophy, while the body is the subject of activity of science and medicine. The body should be treated as a machine. The illness is a disturbance of the components of the human machine - Mechanicism. This is the paradigm of Western and conventional medicine [25]. The root of Cartesian dualism is described in "Discours de La Méthode" (being this idea expressed through the famous sentence "I think, therefore I am" or "cogito, sum"), while the root of Cartesian mechanicism is described in "L'Homme" (Descartes proposed to apply the principle of a mechanical interpretation of the physical world to living things) [26].

However, in the $18^{\text {th }}, 19^{\text {th }}$ and $20^{\text {th }}$ centuries, it occurred some experiments in the brain area by Galvani (who demonstrated the bioelectricity), Golgi (who identified the dendrites (extensions of neurons)), Ramón y Cajal (who proposed the theory of individual neurons), Bois-Reymond and Muller and von Helmholtz (who defended that the neuron could influence others neurons through signals electro-chemicals), Jackson and Broca and Wernicke (who demonstrated that sensory and motor functions could be assigned to certain areas of the brain), Hubel and Wiesel (who contributed to the "mapping" of the human brain), Sperry and Gazzaniga (who demonstrated the connection of perception and "Corpus Callosum") that has led to suggest that the mind and the body are related between them [27]. This idea is the core of the research work of António Damsio [28]. This scientist claims that Descartes's error is related to the separation between the body and the mind, and that they could exist separately from each other. In this regard, António Damásio defends that the emotions and feelings are an important link between the thoughts and the physical body. For example, the feelings and emotions have played a key role in our decision-making and personal choices in the survival of mankind through ages, as well as in the perception and the expansion of awareness of the human being. In summary, the mind of the patient (thoughts and feelings) plays a relevant role on outer reality (which is not relevant in the Cartesian Universe). Despite in the last two centuries have been performed these experiences in the brain area, nowadays, the patients are still treated by conventional and Western medicine in a Cartesian manner, that is, the human body is treated as a machine, where the mind does not play any role in the healing process [29]. 


\section{The usefulness of Integrative Medicine: An overview}

In contemporary society, with the advances of science is expected that human beings will live longer in the future [30]. The question is whether this increase of expectation of life will also correspond to an increase in the quality of life to the patient (biopsycho-spiritual dimensions of the human being): goal \#3 ("To ensure healthy lives and promoting well-being for all, at all ages") of the Sustainable Development Goals (SDG) of the United Nations 2030 Agenda. What remains to be done in this area of research (History of medicine) is to find a "model of Integrative and Transdisciplinary medicine" [31], [32] in order to see the patient in an holistic way: soul, mind and body [33]. In this regard, I have to mention that proper soul-mind-body alignment has a positive effect on the way the chakras operate, which has a beneficial effect on the patient's health [34].

In historical terms, Integrative medicine emerged in the United States in the 1970s and 1980s, notably through the doctors Andrew Weil (from Center for Integrative medicine, University of Arizona) and David Einsenberg (from Harvard University), followed by Daniel Vicario (from San Diego Cancer Center, University of California) whose holistic knowledge of medicine has spread throughout the world. Nowadays, another examples of integrative medicine doctors are Paulo de Lima (from Albert Einstein Hospital, in Brazil), Matthias Girke (from Havelhöe Hospital, in Germany), in the West, and Ram Vishwakarma (from Indian Institute of Integrative medicine, in India), Chen Keji (from Chinese Association of Integrative medicine, in China), in the East, among others [35].

An example of the usefulness of Integrative medicine in contemporary society might be seen in the methods of healing of a patient with a depression [36]. In conventional medicine, the physician gives allopathic drugs (with several side effects) in order to relieve the physical symptoms of depression (the biological dimension of human being), such as ideas of fault/failure, emotional sadness, lack of physical appetite [37]. On the other hand, in mind-body medicine and Ayurveda the physician makes the connection between the mental/emotional pattern and the physical behavior through the "doshas", trying to promote positive thoughts and feelings in a natu- ral way (meditation, contact with friends and family members). In fact, in Ayurveda the effective process of healing only occurs when the patient wants to change the pattern of behavior that led to the depression (mental, emotional, physical) in order to eliminate the causes of the disease (the psychological dimension of human being), as well as allowing to reduce the allopathic drugs (not just the cure but also give quality of life to the patient) and the costs associated with this medication which is not addressed by Western medicine [38]. Moreover, in Ayurveda and mind-body medicine, the body (is not just a machine as claims Western medicine) also plays a relevant role in the development of the consciousness mind of the human being (the spiritual dimension of the human being) as described by Panchakoshas theory and Egg's diagram referred to earlier [39].

\section{Conclusions}

In summary, I should point out that there is an experiment that supports a model of Integrative medicine, namely, the experiment of Alain Aspect and collaborators on the instantaneous communication between two quantum particles correlated by polarization, regardless of their distance (called "quantum nonlocality"), [40] and which Jacobo GrinbergZylberbaum and collaborators [41] repeated through an experiment of telepathic communication between two shamans' brains correlated through meditation. This type of nonlocal experiments are present in the "spontaneous cures" [42], [43] (which conventional medicine can not explain), but whose cause and explanation might be justified through a model of Integrative Medicine [44].

Funding: This research received no external funding.

Conflicts of Interest: The author declare no conflict of interest.

\section{References}

[1] Weil, A. (2017). Health and Healing: The philosophy of Integrative Medicine and Optimum Health. Mariner Books.

[2] Available from www.un.org/sustainabledevelopment.

[3] Lad, V. 2001/2007/2012. Textbook of Ayurveda, Vol.1: Fundamental Principles of Ayurveda (2001); Vol.2:A complete Guide to Clinical Assessment 
(2007); Vol.3: General Principles of Management and Treatment (2012). Ayurvedic Press.

[4] Porter, R. (2006). The Cambridge History of Medicine. Cambridge Univer. Press.

[5] Martins, P. (2017). The history of the Indian sacred book (Atharva-Veda) and its contribution to the Integrative Medicine model. Transdisciplinary Journal of Engineeringes Science, vol. 8, pg-54-59.

[6] Zysk, K. (2010). Medicine in the Veda: Religious Healing in the Veda. Motilal Banarsidass.

[7] Mukhopadhyaya, G. (2003). History of Indian Medicine. Munshiram Manoharlal Publishers, Vol 3.

[8] Dasgupta, S. (1997). A History of Indian philosophy. Motilal Banarsidass. Vol 5.

[9] Chopra, D. (2001). Perfect Health: the Complete Mind/body Guide. New York: Three Rivers Press.

[10] Wujastyk, D. (2003). The roots of Ayurveda. Penguim Classics.

[11] Goleman, D. and Gurin, J. (1993). Mind-Body Medicine. New York: Consumer Reports Books.

[12] Deussen, P. (1906). The History of the Upanishads Religion and Philosophy of India. Dover Publications.

[13] Pribam, K. (1993). Rethinking Neural Networks: Quantum Fields and Biological Data, Proceedings of the First Appalachian Conference on Behavioral Neurodynamics, Lawrence Erbaum Associates.

[14] Hameroff, S. and Penrose, R. (1996). Orchestrated reduction of quantum coherence in brain microtubules - a model for consciousness, Toward a Science of Consciousness: Contributions from the 1994 Tucson Conference.

[15] Goswami, A. (2004). The Quantum Doctor. Hampton Roads Publishing Company.

[16] Nicolescu, B. (1985). Nous, la Particule et le Monde. Paris: Le Mail.

[17] Frawley, D. (1997). Ayurveda and the Mind: The Healing of consciousness. Lotus Press.

[18] Figure 1 from www.ayurvedaposters.com, N0. 49Kosha Poster (acknowledgements to Mr. Aaron Staengel to grant authorization to publish this photo).

[19] Nicolescu, B. (1996). Levels of Complexity and Levels of Reality, in Bernard Pullman (ed.), The Emergence of Complexity in Mathematics, Physics, Chemistry and Biology, Vatican City, Pontificia Academia Scientiarum.

[20] Motoyama, H. (2018). Theories of the chakras: Bridge to higher consciousness. New Age Books.
[21] Figure 2 from https://kennethsrensen.dk/en/therebirth-of-the-soul-with-roberto-assagioli/ (aknowledgements to Dr. Kenneth Sörensen to grant authorization to publish this photo).

[22] Assagioli, R. (1976). Psychosynthesis: A Manual of Principle and Techniques. Penguin Books.

[23] Jung, C. (1947). On the Nature of the Psyche. London: Ark Paperbacks.

[24] Kelly, K. (2009). The History of Medicine: The Middle Ages (500-1450). Facts on File.

[25] Queiroz, M. (1986). The mechanistic paradigm of modern western medicine: an anthropological perspective. Revista de Saúde Pública, 20(4): 309-317.

[26] Ramozzi-Chiarottino, Z. and Freire, J.-J. (2013). O dualismo de Descartes como princpio de sua Filosofia Natural. Estudos Avanados, 27 (79): 157-165.

[27] Kandell, E. and Schwartz, J. and Jessel, T. et al. (2012). Principles of Neural Science. McGraw-Hill.

[28] Damásio, A. (2005). Descartes's Error: Emotion, Reason and the Human Brain, Penguin Books.

[29] Benedict, F. (2018). The influence of Muscular and Mental Work on Metabolism and the Efficiency on the Human Body as a Machine. Forgotten Books.

[30] Cohen, I.R. and Lajtha, A. and Lambris, J.D. and Paoletti, R. and Rezaei, N. (2018). Advances in Experimental Medicine and Biology. Springer.

[31] Bell, I.R. and Caspi O. and Schwartz, G.E. and Grant, K.L. and Gaudet, T.W. and Rychener, D. and Maizes, V. and Weil, A. (2002). Integrative medicine and systemic outcomes research: issues in the emergence of a new model for primary health care. Arch Intern Med, 162(2):133-140.

[32] Snyderman, R. and Weil, A.T. (2002). Integrative medicine: bringing medicine back to its roots. Arch Intern Med, 162(4):395-397.

[33] McLean, B. (2017). Integrative Medicine: The return of the Soul to healthcare. Balboa Press.

[34] Neves e Sousa, L. (2002). Integrative Medicine: The Crakras and soul-mind-body alignment. Personal communication.

[35] Phalen, K. 2012. Integrative medicine: Achieving Wellness through the best of Eastern and Western Medical practices. Tuttle Publishing.

[36] Rakel, D. (2017). Integrative Medicine. Elsevier.

[37] American Medical Association. (2003). American Medical Association (AMA) Complete Medical Encyclopedia. Random House Reference.

[38] Verma, V. (1995). Ayurveda: A Way of Life. Red Wheel/Weiser. 
[39] Gold, E. J. (2008). The Human Biological Machine as a Transformational Apparatus: Talks on Transformational Psychology (Consciousness Classics). Gateway Books \& Tapes.

[40] Aspect, A. and Dalibard, J. and Roger, G. (1982). Experimental test of Bell's inequalities using time-varying analyzers. Physical Review Letters, 49(25):1804-1807.

[41] Grinberg-Zylberbaum, J. and Delaflor, M. and Attie, L. and Goswami, A. (1994). Einstein-PodolskyRosen paradox in the human brain: The transferred potential. Physics Essays, 7(4): 422-428.

[42] Weil, A. (1995). Spontaneous Healing. Nova York:Knopf.

[43] O'Reagan, B. (1987). Spontaneous remission: Studies of Self-Healing. Institute of Noetic Sciences.

[44] Templeman, K. (2011). Integrative medicine models in contemporary primary health care. Complementary Therapies in Medicine, (Elsevier), 19(2): 84-92.

\section{About the Author}

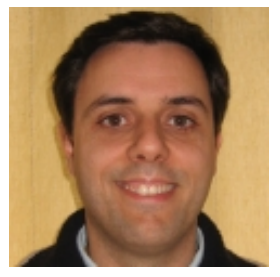

Dr. Paulo Nuno Martins, a Chemical Engineer (Instituto Superior Técnico, University of Lisbon) and a PhD in History and Philosophy of Science (Faculty of Sciences and Technology, New University of Lisbon). He studied for 3 years Oriental languages and culture (Indian, Chinese, Japanese, Arabic) and he is currently a researcher in History of science at Interuniversity Center for History of Science and Technology, New University of Lisbon, Portugal (CIUHCT-UNL) (http://orcid.org/0000-00022670-3172). Dr. Paulo Nuno Martins is a member of CIRET (centre international de recherches et d'études transdisciplinaires), Paris. 